\title{
Effect of simulation on the clinical competence of Swedish ambulance nurses
}

\author{
${ }^{1}$ Magnus Andersson Hagiwara MScN, ${ }^{1}$ Anna Kängström MScN, ${ }^{1,2}$ Anders Jonsson MD, ${ }^{1,2}$ Lars Lundberg MD \\ Affiliations: \\ ${ }^{1}$ School of Health Sciences, University of Borås, Sweden \\ ${ }^{2}$ Swedish Armed Forces Centre for Defence Medicine, Sweden
}

\section{ABSTRACT \\ Introduction}

Simulation has become an established method for education and training of Emergency Medical Services personnel in different skills such as advanced airway techniques, also in evaluation and initial care of stroke patients and in pre-hospital trauma. Simulation can be a useful method to improve learning. To our knowledge, there are only a few studies that relate simulation to the effect on clinical skills. The aim of the present study was to investigate the effect of simulation on the clinical competence in a pre-hospital trauma care course for ambulance nurses.

\section{Methods}

The study was performed using a before-after design. Seventeen ambulance nurse students who participated in a trauma care course were evaluated in two simulated trauma cases. All subjects had passed the initial theoretical part of the course. The pre-test was performed in the beginning of the following part of the course involving simulation and the post-test at the end of the course. The analysis was performed by assessment of performance, as seen on video-tapes from the pre-tests and the post-tests. A validated instrument was used to determine the level of student's clinical competence. Paired $t$-test was used to confirm differences between the pre-test and post-test results.

\section{Results}

There was a significant increase in the over-all results for the post-test, with a difference of 1.12 points $(t=4.642, d f=16, p=0.001)$ Situation Awareness, Patient Assessment and Decision Making showed the most pronounced improvements.

\section{Conclusion}

The results imply that simulation in addition to traditional theoretical education improves the clinical competence of the students, in comparison to traditional education and training without any significant amount of simulation.

\section{Keywords}

Clinical competence, emergency medical services, nursing education, pre-hospital, simulation

\section{INTRODUCTION}

Pre-hospital care is a part of health care which is characterised by a general lack of information, a large variation of medical conditions, care in sometimes austere environments and a high degree of emergencies (1). These factors contribute to the complexity of health care that requires effective clinical judgment by health care practitioners. Several studies have shown that cognitive mistakes and errors in the evaluation and treatment of patients are the largest threats to patient safety in pre-hospital care (2-4). Therefore 
researchers recommend simulation as a method to prevent errors in the evaluation of patients, as well as in the decision-making, which in turn can increase patient safety (5).

Simulation is not a new pedagogical method. In certain high-security areas such as the aviation industry, the nuclear power industry and in the military environment, simulation has been used for many years as a method to minimize risks and to reduce the number of severe and possibly fatal mistakes (6).

There are three types of simulation in health care: (a) Low-fidelity simulation, i.e. simple training models for basic procedures such as the insertion of a peripheral cannula,

(b) Medium-fidelity simulation which allows training of more complex functions, and sometimes evaluation of procedures performed, for example mannequins for cardio-pulmonary resuscitation (CPR), and

(c) High-fidelity simulation (HFS).

HFS mannequins are characterized by their ability to mimic most bodily functions, such as breathing with adequate breath sounds and chest movements, heart sounds, palpable arterial pulses and different types of injuries. The mannequins have a high degree of realism and can be programmed to respond to different kinds of treatment. There are advanced modules for debriefing and evaluation, logging of vital signs, events and procedures performed. Videos and sound recordings can be analysed at a later stage (7).

Simulation has become an established method for education and training of Emergency Medical Services (EMS) personnel in different skills such as advanced airway techniques (8), in the evaluation and initial care of stroke patients (9) and in pre-hospital trauma management (10). Simulation has also been used as a model for accreditation of EMS personnel $(11,12)$.

It is further reported that simulation is an effective pedagogical method for teaching students technical skills $(8,13,14)$, team training $(6,15)$ and development of cognitive skills (16), as well as exploring ethical dilemmas (17). It has also been shown that simulation can be a useful method to improve theoretical learning $(10,18)$. However, there are no studies that can relate simulation to the effect on real patients (19).

In addition, it is difficult to estimate the exact costs for simulation. Any education or training involving HFS has the potential to increase patient safety (20) and studies taking into account eventual costs for health care related injuries might give another picture for the total costs of simulation. An increased use of simulation for education and training of ambulance nurses and paramedics, as well as for any other programme or course for nurses will certainly incur higher costs. In order to justify these higher costs, it is essential to know how effective simulation is.

The aim of the present study was to investigate the effect of simulation on the clinical competence of ambulance nurses in a pre-hospital trauma care course in Sweden.

\section{METHODS}

\section{Context and Participants}

The participants in this study were students in a two-part Trauma Care Course for ambulance nurses. The first part is theoretical and given as a half-day lecture over four weeks. Lectures topics included ballistic trauma, as well as evaluation and initial care for traumatised children, adults and elderly patients. There are also comprehensive lectures on airway problems, chest injuries, circulation and bleeding, abdominal injuries, burns, hypothermia and drowning. All lectures were given by experts in the respective fields. The students' theoretical knowledge of prehospital trauma care is assessed in a written examination at the end of the course.

The second part is practical, starting with two days at the university campus, where the students train at eight different skill stations. At each skill station there is an opportunity to use a low to high fidelity mannequin to assess skills such as immobilisation and realignment of fractures, and basic and advanced airway procedures. Different types of simulation, ranging from low-fidelity to high-fidelity, are used in the individual skill stations. The last part of the course is located at the nearby Rescue Services drill-ground, where the students train together with fire-fighters. This training consists of simulated exercises such as extrication of casualties from road traffic accidents. During the afternoon, the students were exposed to two full-scale exercises with a mix of moulage patients and HFS mannequins (Laerdal® SimMan $2 \mathrm{G} \AA$ ), where they will act as EMS personnel. All exercises include debriefing, where the students reflect about the simulation exercise and are given feedback by the instructors.

The final practical examination consists of two different full-scale exercises, where the students are sent in ambulances to a fictitious accident scene. They will encounter a scenario with a number of casualties in the form of moulage patients. In each examination there is also an individual case where the students have to 
evaluate and initiate initial treatment for a casualty represented by a HFS mannequin.

All 42 students in the trauma care course were invited to participate in the present study, where 17 (40\%) accepted.

\section{Design}

The study was performed using a before-after design. A HFS pre-test was performed during the first day of the practical part of the course. All participant's had passed the theoretical part of the course. Each study participant was individually evaluated with a simulated trauma case and initiation of initial care. There was an assistant attending the participant, played by one of the authors. This rather passive assistant was able to perform all procedures asked for, but took no initiatives and gave no hints. On the incident site was a witness to the accident, who could give additional information in response to questions, as well as help with simple non-medical procedures. In order to minimise variation, one single person acted as mannequin operator in all simulation sessions, pre-tests, as well as post-tests. In order to keep the simulation sessions identical, the same script was used for all tests. Efforts were made to make the scene as realistic as possible by providing visual cues in the form of maps, photographs and objects found at the scene.

The simulated mannequin patient was a victim of a high-speed motorcycle accident. It was reported that the casualty was found lying on their back with the helmet on. They were unconscious and had a partial airway obstruction that had to be immediately dealt with. When correct basic airway procedures were performed, breathing gradually improved. Vital parameters were otherwise normal and stable. The ambulance personnel had access to oxygen, relevant monitoring devices, drugs and immobilisation equipment. The study participants were asked to verbally specify which procedures had to be done prior to loading the patient into the ambulance and which procedures could be done later inside the ambulance. The scenario was ended after 10 minutes. This time limit was set with respect to the time a severely injured patient is expected to have been removed from the scene of the accident (21).

The post-test on the last day of the course was performed in a similar way. In the post-test HFS scenario, a man had fallen down a ladder, resulting in a head injury and a thoracic injury including unilateral rib fractures and an uncomplicated pneumothorax.

All simulations in the pre-test and post-test scenarios were video-taped for later evaluation of the performance.

\section{Evaluation Instrument}

For evaluation, the Global Rating Scale for the Assessment of Paramedic Clinical Competence, $(12,22)$ was used. To our knowledge this is the only validated instrument that measures prehospital clinical competence. This instrument is reported to have an interrater reliability (Kappa) of 0.75-0.94 and an internal consistency (Cronbach's alpha coefficient) of 0.53-0.89. The content validity was established by a modified Delphi process. The instrument covers seven different items. All items were assessed on a 7-point Likert scale, where 1 is unsafe and 7 exceptional. A rating of 3 is a failure, while a rating of 4 means that the student has passed, but more training is recommended. Item 1 evaluates the student's ability to observe and gather relevant data, including risk assessment. Item 2 evaluates the student's ability to take a structured patient history. The evaluation of the patient's medical condition and the need for initial treatment are evaluated in Item 3, while decision making is evaluated in Item 4. The last three items cover the student's use of available resources, communication skills, and general safety during the performed procedures.

\section{Ethical Considerations}

The study was approved by the University Ethical Committee. Informed consent was obtained from all study subjects in oral and written form.

\section{Analysis}

The performance as seen on video-tapes from the pre-tests and the post-tests was assessed by using the Global Rating Scale protocol. Ten videotapes were assessed individually by two of the authors. The interrater reliability (IR) was calculated after the first analysis. The IR Kappa score was $0.60(p=0.071)$. A Kappa result of 0.60 is considered moderate consistence (23).

The remaining video-tapes were divided between the same authors and analysed separately. Paired $t$-test were used to identify differences between pre-test and post-test results. Descriptive statistics were used for the demographical data of the study participants. A p-value of $<0.05$ was considered significant in all statistical tests. All statistical analyses for this study were performed with SPSS Version 19 (IBM, Armonk, NY).

\section{RESULTS}

The participants of this study had a mixed background, ranging from 20 years previous experience of ambulance work to no previous EMS experience at all (Table 1). 


\begin{tabular}{lll} 
& $\begin{array}{l}\text { Mean } \\
\text { difference } \\
\text { between pre } \\
\text { and post } \\
\text { test scores }\end{array}$ & Significance \\
\hline Item & 1.29 & $\mathrm{P}=<0.001$ \\
Hituation Awareness & 1.12 & $\mathrm{P}=0.001$ \\
$\begin{array}{l}\text { Patient Assessment } \\
\text { Decision Making }\end{array}$ & 1.29 & $\mathrm{P}=<0.001$ \\
$\begin{array}{l}\text { Resource Utilization } \\
\text { Communication }\end{array}$ & 1.35 & $\mathrm{P}=<0.001$ \\
$\begin{array}{l}\text { Procedural Skill } \\
\text { Overall Clinical }\end{array}$ & 1.35 & $\mathrm{P}=0.024$ \\
$\begin{array}{l}\text { Performance } \\
\text { Table 2: Mean difference between Post-test and Pre-test } \\
\text { scores }\end{array}$ & 1.06 & $\mathrm{P}=0.05$ \\
\hline
\end{tabular}

Years of EMS experience

$52.9 \%$

Male

9

$47.1 \%$

Average age

32.1 years

Years of RN experience

$\begin{array}{lll}0-1 \text { year } & 1 & 5.9 \% \\ 1-5 \text { years } & 9 & 52.9 \% \\ 5-10 \text { years } & 5 & 29.4 \% \\ >10 \text { years } & 2 & 11.8 \%\end{array}$

No EMS experience

10

$<5$ years

$58.8 \%$

5-10 years

2

$>10$ years
$17.6 \%$

$11.8 \%$

$11.8 \%$

Table 1: Demographic Characteristics of Participants $(\mathrm{N}=17)$

The results from the evaluations before and after the intervention show a progression of the students' clinical competence (Table 2). There was a significant increase in the over-all results in the post-test, with a difference of 1.12 points $(t=4.642, d f=16, p=0.001)$. Except the item communication, there was a general increase in the results for all items covered in the validation instrument. However, the following three items showed the most pronounced improvement:

- Situation Awareness. This item addresses the observed ability to read the situation and to gather adequate information needed for evaluation, such as safety issues, impact, velocities, etc. The difference between pretest and post-test scores was 1.29 points $(t=$ 4.600, $\mathrm{df}=16, \mathrm{p}=0.001$ ).

- $\quad$ Patient Assessment. This item measures the ability to make a structured and safe evaluation of a patient, with the use of adequate methods for the situation. The difference between pre-test and post-test scores was 1.29 points $(t=5.416, d f=16$, $\mathrm{p}=0.001$ ).

- Decision Making. This item focused on the ability to make safe and correct decisions that improved the patient outcome, for example, decisions regarding what should be done on site and what is better done in the ambulance on route to the hospital. The difference between pre-test and post-test scores was 1.35 points $(t=4.386, d f=16, p=0.001)$.

\section{DISCUSSION}

\section{Results}

The results indicate that the students' clinical competence had increased after the simulation sessions. It is possible that theoretical education by itself is not sufficient to prepare an ambulance nurse for future clinical work. In the clinical practicums it is also unlikely that the student will encounter the different patient types that they need to enable them to handle future on road situations, for example, patients with a stroke, hip fractures, severe trauma, cardiac arrest, myocardial infarction, childbirth and different child emergencies.

Severe trauma is not one of the most common incident types for EMS personnel in Sweden. However, a rapid and correct pre-hospital response is of utmost importance for the patient's outcome in severe trauma (24). It is difficult to build experience and competence for incident types that are not seen on a regular basis. For this reason, simulation becomes an important model for building a personal action plan. A previous study has shown that course participants in prehospital trauma courses have been very positive to HFS, that their self-confidence has increased, and that the results in written examinations were improved (10).

We have identified three possible reasons why simulation works as an effective pedagogical method for education and training closely related to pre-hospital care. 


\section{Reflection}

Reflection is a method that has been suggested as a possible way to reduce the gap between theory and practice $(25,26)$. Reflection aims at visualisation of theory and its connection to practice (26). A number of methods have been suggested to introduce reflection in nursing schools. Reflection and feedback is an essential part of learning. The role of reflection has also been discussed for simulation $(27,28)$. One obvious advantage of simulation in the education and training of ambulance nurses is that simulation makes it possible for the student to reflect on their own learning, while evaluating medical parameters and performing advanced technical procedures.

\section{Learning by Experience}

Recent cognitive research has shown that professionals with special skills do not make decisions based on the analysis of possible alternatives, instead, decisions are based on experience (29). Experienced decision makers seem to mentally simulate different solutions to a certain problem with this mental simulation based on previous experience. This model allows the decision maker to make rapid decisions.

By exposing the student to many simulation sessions, the decision making process can be improved. Interestingly, Decision Making was the item where the largest benefit from the simulation intervention was seen in our study. Constructivist theories describe the human being as an active constructor who tries to develop by gaining knowledge. By increasing experience, the understanding of how tasks can be performed is also increasing. The increased understanding is then transferred into new performance, by a continuous cycle of repeating, observing and evaluating (30).

\section{Learning by Doing}

The findings in this study support the notion that learning by doing is valuable in the training of ambulance nurses. In all types of vocational training, a certain amount of learning by doing should be present (31). By letting the students perform profession-related practical skills in a realistic environment, a critical approach and behaviour is stimulated. The possibility to assess the individual practical skills of the students is also important. Learning by doing provides a potential foundation for the correlation between repeated training and acquired skills (32).

\section{Limitations of the Study}

A limitation for many simulation studies, including the present study, is the artificial environment provided. In future studies, special efforts should be made to create a study environment as realistic as possible.

One specific limitation of this study design was that there was no control group. To further evaluate the effects of simulation on the clinical competence of ambulance nurses, a comparison should be made with a control group that receive education in a more traditional form, such as lectures and seminars.

Another limitation is that the evaluation of performance on the video-tapes was not blind, which is a well-known bias since the evaluators consciously or unconsciously might favour the group they think should obtain the best results (33). In this study, the evaluation of the videotapes was performed by two of the authors. In order to reduce bias, 10 video-tapes were evaluated by both persons and interrater reliability was calculated upon the obtained results. The remaining video-tapes were divided between the two evaluators.

Finally, only 17 out of 41 students agreed to participate in the study. It is unclear how this might be reflected in the individual study results. There is of course a certain risk that students with better self-confidence felt easier in participation. If this is the case, then the positive effect of simulation might be even larger than what has been seen in this study.

\section{CONCLUSION}

The results imply that simulation in addition to traditional theoretical education improves the clinical competence of students in comparison to traditional education and training without any significant amount of simulation. The three major areas of improvement from simulation were; Situation Awareness, Patient Assessment and Decision Making. The results of this study could be applied to other courses during basic and specialist training for paramedics and ambulance nurses.

\section{CONFLICT OF INTEREST}

The authors declare they have no conflict of interest.

\section{ACKNOWLEDGEMENTS}

We would like to thank the students who participated in the study. We would also like to thank Andreas Claesson who assisted during the two simulation sessions. 


\section{REFERENCES}

1. Franklin A, Liu Y, Li Z, et al. Opportunistic decision making and complexity in emergency care. Journal Of Biomedical Informatics 2011;44(3):469-76.

2. Atack L, Maher J. Emergency medical and health providers' perceptions of key issues in prehospital patient safety. Prehospital Emergency Care. 2010;14(1):95-102.

3. Fairbanks RJ, Crittenden CN, O'Gara KG, et al. Emergency medical services provider perceptions of the nature of adverse events and near-misses in out-of-hospital care: an ethnographic view. Academic Emergency Medicine. 2008;15(17):633-40.

4. Wang HE, Fairbanks RJ, Shah MN, Abo BN, Yealy DM. Tort claims and adverse events in emergency medical services. Annals Of Emergency Medicine. 2008;52(3):256-62.

5. Bigham BL, Bull E, Morrison M, et al. Patient safety in emergency medical services: executive summary and recommendations from the Niagara Summit. Canadian Journal Of Emergency Medical Care. 2011;13(1):13-8.

6. Gaba DM. The future vision of simulation in health care. Quality and Safety in Health Care. 2004;13:(suppl 1)2-10.

7. Yuan HB, Williams BA, Fang JB. The contribution of high-fidelity simulation to nursing students' confidence and competence: a systematic review. International Nursing Review. 2012;59(1):2633.

8. Hall RE, Plant JR, Bands CJ, Wall AR, Kang J, Hall CA. Human Patient Simulation Is Effective for Teaching Paramedic Students Endotracheal Intubation. Academic Emergency Medicine. 2005;12(9):850-5.

9. Gordon DL, Issenberg SB, Gordon MS, LaCombe D, McGaghie WC, Petrusa ER. Stroke training of prehospital providers: an example of simulation-enhanced blended learning and evaluation. Medical Teacher. 2005;27(2):114-21.

10. Kim TE, Reibling ET, Denmark KT. Student perception of high fidelity medical simulation for an international trauma life support course. Prehospital And Disaster Medicine. 2012;27(1):27-30.

11. McLaughlin SA, Doezema D, Sklar DP. Human Simulation in Emergency Medicine Training: A Model Curriculum. Academic Emergency Medicine. 2002;9(11):1310-8.

12. Tavares $\mathrm{W}$, Boet $S$, Theriault $R$, Mallette $T$, Eva KW. Global Rating Scale for the Assessment of Paramedic Clinical Competence. Prehospital Emergency Care. 2012;17(1):57-67.
13. Barsuk D, Ziv A, Lin G, et al. Using advanced simulation for recognition and correction of gaps in airway and breathing management skills in prehospital trauma care. Anesthesia And Analgesia. 2005;100(3):803.

14. Wang EE, Quinones J, Fitch MT, et al. Developing Technical Expertise in Emergency Medicine-The Role of Simulation in Procedural Skill Acquisition. Academic Emergency Medicine. 2008;15(11):1046-57.

15. LeRoy Heinrichs W, Youngblood P, Harter PM, Dev P. Simulation for team training and assessment: case studies of online training with virtual worlds. World Journal Of Surgery. 2008;32(2):161-70.

16. Onda EL. Situated Cognition: Its Relationship to Simulation in Nursing Education. Clinical Simulation in Nursing. 2012;8(7):273-80.

17. Chen RP. Moral imagination in simulationbased communication skills training. Nursing Ethics. 2011;18(1):102-11.

18. Li CH, Kuan WS, Mahadevan M, DanielUnderwood L, Chiu TF, Nguyen HB. A multinational randomised study comparing didactic lectures with case scenario in a severe sepsis medical simulation course. Emergency Medicine Journal. 2012;29(7):559-64.

19. Teteris E, Fraser K, Wright B, McLaughlin K. Does training learners on simulators benefit real patients? Advances In Health Sciences Education: Theory And Practice. 2012;17(19):137-44.

20. Aggarwal R, Mytton OT, Derbrew M, et al. Training and simulation for patient safety. Quality \& Safety In Health Care. 2010;19(Suppl 2):34-43.

21. PHTLS: prehospital trauma life support. St. Louis, Mo.: Elsevier Mosby Jems; 2011.

22. Tavares. W LV, Justin Mausz. J, Sun. V, Eva. KW. Simulation-based Assessment of Paramedics and Performance in Real Clinical Contexts. Prehospital Emergency. Care. 2013 (early online).

23. Byrt T. How good is that agreement? Epidemiology 1996;7(5):561.

24. Murad M, Larsen S, Husum H. Prehospital trauma care reduces mortality. Ten-year results from a time-cohort and trauma audit study in Iraq. Scandinavian Journal Of Trauma, Resuscitation And Emergency Medicine. 2012;20(1):13.

25. Gustafsson C, Fagerberg I. Reflection, the way to professional development? Journal Of Clinical Nursing. 2004;13(3):271-80.

26. Ekebergh M, Lepp M, Dahlberg K. Reflective learning with drama in nursing education--a Swedish attempt to overcome the theory praxis gap. Nurse Education Today. 2004;24(8):622-8. 
27. Sanford PG. Simulation in Nursing Education: A Review of the Research. The Qualitative Report. 2010;15(4):1006-11.

28. Kneebone RL, Nestel D, Vincent C, Darzi A. Complexity, risk and simulation in learning procedural skills. Medical Education. 2007;41(8):808-14.

29. Klein G. Sources of power : how people make decisions. Cambridge, Mass.: MIT; 1999.

30. Bron A, Wilhelmson L. Lärprocesser i högre utbildning. Stockholm: Liber; 2005.

31. Race P. The lecturer's toolkit : a practical guide to learning, teaching and assessment. London: Routledge Falmer; 2001.

32. David G, Brachet T. Retention, Learning by Doing, and Performance in Emergency Medical Services. Health Services research. 2009;44(3):902-25.

33. Kazdin AE. Research design in clinical psychology. Boston, MA: Allyn and Bacon; 2003. 